Article

\title{
Interphase Surface Stability in Liquid-Liquid Membrane Contactors Based on Track-Etched Membranes
}

\author{
Stepan Bazhenov ${ }^{1, *}$, Olga Kristavchuk ${ }^{2} \mathbb{D}$, Margarita Kostyanaya ${ }^{1}$, Anton Belogorlov ${ }^{1,3,4} \mathbb{D}$, Ruslan Ashimov $^{1} \mathbb{D}$ \\ and Pavel Apel ${ }^{2}$
}

check for updates

Citation: Bazhenov, S.; Kristavchuk, O.; Kostyanaya, M.; Belogorlov, A.; Ashimov, R.; Apel, P. Interphase Surface Stability in Liquid-Liquid Membrane Contactors Based on Track-Etched Membranes. Membranes 2021, 11, 949. https://doi.org/ 10.3390/membranes11120949

Academic Editor: Alessandra Criscuoli

Received: 6 November 2021

Accepted: 26 November 2021

Published: 30 November 2021

Publisher's Note: MDPI stays neutral with regard to jurisdictional claims in published maps and institutional affiliations.

Copyright: (c) 2021 by the authors. Licensee MDPI, Basel, Switzerland. This article is an open access article distributed under the terms and conditions of the Creative Commons Attribution (CC BY) license (https:/ / creativecommons.org/licenses/by/ $4.0 /)$.
1 A.V. Topchiev Institute of Petrochemical Synthesis, Russian Academy of Sciences, 119991 Moscow, Russia; marille@ips.ac.ru (M.K.); aabelogorlov@ips.ac.ru (A.B.); ashimov999@gmail.com (R.A.)

2 Flerov Laboratory of Nuclear Reactions, Joint Institute for Nuclear Research, 141980 Dubna, Russia; kristavchuk@jinr.ru (O.K.); apel@jinr.ru (P.A.)

3 Molecular Physics Department, National Research Nuclear University Moscow Engineering Physics Institute, 115409 Moscow, Russia

4 Research Institute for Graphite-Based Structural Materials "NIIgrafit" (JSC "NIIgrafit"), 111524 Moscow, Russia

* Correspondence: sbazhenov@ips.ac.ru

\begin{abstract}
A promising solution for the implementation of extraction processes is liquid-liquid membrane contactors. The transfer of the target component from one immiscible liquid to another is carried out inside membrane pores. For the first time, highly asymmetric track-etched membranes made of polyethylene terephthalate (PET) of the same thickness but with different pore diameters (12.5-19 nm on one side and hundreds of nanometers on the other side) were studied in the liquidliquid membrane contactor. For analysis of the liquid-liquid interface stability, two systems widely diverging in the interfacial tension value were used: water-pentanol and water-hexadecane. The interface stability was investigated depending on the following process parameters: the porous structure, the location of the asymmetric membrane in the contactor, the velocities of liquids, and the pressure drop between them. It was shown that the stability of the interface increases with decreasing pore size. Furthermore, it is preferable to supply the aqueous phase from the side of the asymmetric membrane with the larger pore size. The asymmetry of the porous structure of the membrane makes it possible to increase the range of pressure drop values between the phases by at least two times (from 5 to $10 \mathrm{kPa}$ ), which does not lead to mutual dispersion of the liquids. The liquid-liquid contactor based on the asymmetric track-etched membranes allows for the extraction of impurities from the organic phase into the aqueous phase by using a $1 \%$ solution of acetone in hexadecane as an example.
\end{abstract}

Keywords: track-etched membrane; liquid-liquid membrane contactor; liquid-liquid displacement

\section{Introduction}

Today, membrane technologies occupy one of the most intensively developing technological areas and find various applications in industry [1]. A striking example is the membrane contactor, which allows for the implementation of the separation process or a chemical transformation. In the membrane contactor, the membrane acts as an interface between two phases [2]. The main advantages of membrane contactors are independent phase flow rates within a wide range without mutual dispersion of phases and large specific mass-transfer areas per module volume-up to $10,000 \mathrm{~m}^{2} / \mathrm{m}^{3}$. Moreover, they lead to increased mass-transfer coefficients of the required component from one phase to another and, consequently, to compact separation modules [3]. Gas-liquid membrane contactors are already widely used for various applications, including blood oxygenation $[4,5]$, the removal of acid gases $\left(\mathrm{CO}_{2}, \mathrm{H}_{2} \mathrm{~S}, \mathrm{SO}_{2}\right)$ from gaseous media [6,7], the removal of dissolved gases from liquids [8,9], and the separation of saturated and unsaturated hydrocarbons [10]. 
Many reviews of recent years [3,11-14] are devoted to membranes for gas-liquid membrane contactors and their application areas.

Liquid-liquid membrane contactors are the second critical application, where the mass transfer between two liquid phases is realized, while the phases can be both miscible and immiscible. In the first case, contact between miscible liquids on a porous membrane is realized, where the mass transfer of the target component is carried out in the gas-filled membrane pores. This is the case for several membrane distillation configurations [15], which have emerged as an independent field of membrane science. Other examples are the removal of ammonia from wastewater by sulfuric acid solutions [16,17], the delivery of dissolved carbon dioxide into the growth medium of micro-organism cultures (algae and cyanobacteria) [18], and juice concentration [19].

In the second case, two immiscible liquid phases (mainly aqueous and organic) are in contact on porous membranes. Therefore, this case attracts a lot of attention since the advantages of membrane contactors can be translated into the extraction of various substances [20]. The foundations of liquid-liquid membrane extraction (LLME) were built in the mid-1980s by the pioneering work of the K. Sirkar [21] and E.L. Cussler [22] groups. Today, its application is highly diverse and includes the separation of metals [23] from wastewater, the removal of organic acids, alcohols, and ketones from fermentation broths [24,25], and the extraction of various pharmaceuticals, hormones [26], and antibiotics [27] from aqueous solutions. Moreover, this method could be used to solve various petrochemical problems. For example, as shown recently, it is possible to separate sulfurcontaining components from oil [28] and aviation fuels [29]. At the same time, liquid-liquid membrane contactors can be applied to purify biodiesel fuel from unreacted components (rapeseed oil, methanol, glycerin) [30].

In membrane liquid-liquid contactors-extractors, the transfer of the target (most often non-volatile) component occurs during direct contact of the phases at the mouths or inside the membrane's pores. As in the case of gas-liquid contactors, the stability and controllability of the mass-transfer interface in the membrane pores (indicated by the absence of mutual dispersion of phases) are the keys to the efficient operation and scalability of the separation equipment. Special features of the phase contact depend on the technological parameters of the membrane-extraction system (linear phase flow rates, the pressure drop between phases, liquid-liquid interfacial tension, the process duration). They also depend on membrane functional parameters (thickness, pore size and geometry, structural asymmetry, hydrophilicity/hydrophobicity of the pore surface, and affinity for contacting liquids). Some of these parameters were studied in the early works of Professor Sirkar's group. For example, in [31], the authors revealed the effects of the pore size and tortuosity of polypropylene (PP) and polytetrafluoroethylene (PTFE) membranes in combination with varying the liquid velocity and pressure drop. In [32,33], the effect of the hydrophilicity/hydrophobicity of the membrane material on the process parameters was evaluated. The authors used regenerated cellulose/cellulose acetate (hydrophilic), PP, and PTFE (hydrophobic) membranes. Nevertheless, the use of membranes made of various materials for this kind of research suffers from a significant drawback.

The material plays a primary role in the organization of the pore structure of the membrane, from which a logical consequence follows: membranes made of different materials have an incomparable porous structure. For example, commercial hydrophobic PP and PTFE membranes are obtained mainly by extrusion of a polymer melt followed by stretching, which leads to the formation of symmetric slit pores [34,35]. On the other hand, hydrophilic porous membranes, including cellulose derivatives, are obtained by a more common phase inversion technique using nonsolvents [36,37]. In this process, a symmetric/asymmetric spongy and/or finger-like pore structure of the membrane is obtained. As a result, conclusions about the relationship between the functional properties of the membrane's porous structure and the technological parameters of the membrane contactor system are drawn based on a comparison of membranes with incomparable porous structures and may be incomplete. 
To fill this gap, in this work, for the first time, asymmetric track-etched membranes made of polyethylene terephthalate (PET) were investigated in the mode of a liquid-liquid membrane contactor.

Among the asymmetric membranes, those produced using the track-etching method possess a number of special properties. The track-etching technique provides the possibility of fabricating membranes with precisely determined structural characteristics, including thickness, number of pores, and pore geometry (shape, orientation, symmetry/asymmetry) [38]. Track-etched membranes have a large number of applications. For example, hydrophobized track-etched membranes have much potential in membrane distillation. Due to their properties, such membranes can be used as model membranes for the development and confirmation of theoretical mass, heat transfer, liquid entry pressure, and fouling. Track-etched membranes also have a wide range of applications in the ultrafiltration and microfiltration of liquids and gases; in the analytical control of substances; and in the food and pharmaceutical industries, microelectronics, and other areas of science and industry [39]. Both symmetric and asymmetric small-pore track-etched membranes are widely employed to study the ionic transport phenomena in nanoscale volumes, to build nanofluidic devices, such as molecular sensors, pumps and gates, and logical elements [38], and to develop various new processes, such as electro-baromembrane ion separation [40]. Thus, in [41], a hybrid electro-baromembrane process was applied to separate monovalent cations $\left(\mathrm{K}^{+} /\right.$rhodamine and $\left.\mathrm{K}^{+} / \mathrm{Li}^{+}\right)$. For that, a track-etched membrane with 40 -nm pores produced from PET was used. This is an example of a fundamentally new application of small-pore track-etched membranes. Selective $\mathrm{K}^{+} / \mathrm{Mg}^{2+}$ separation was performed on track-etched polycarbonate membranes with 30-nm pores modified by adsorption of poly(styrene sulfonate) (PSS)/protonated poly(allylamine) (PAH) films [42] The study [43] concerns $\mathrm{Li}^{+} / \mathrm{K}^{+}$separation by using polycarbonate track-etched membranes containing cylindrical pores with nominal $30-\mathrm{nm}$ or $10-\mathrm{nm}$ diameters. Such pores are small enough to provide strong anion exclusion throughout the pore at low ionic strength. This exclusion leads to large streaming potentials and high $\mathrm{Li}^{+} / \mathrm{K}^{+}$selectivities. At the same time, the pores are large enough to allow sufficiently high flow rates under readily available transmembrane pressures.

The performance of asymmetric nanopores in a specific application critically depends on the pore geometry, especially on the shape and size of the narrow part of the pore. The asymmetric track-etched membranes can be produced using either one-sided (also referred to as asymmetric) etching [44] or surfactant-controlled etching [45] of ion tracks in a polymer foil. Both methods allow for the fabrication of highly asymmetric channels with openings on the nanometer scale at one end and 1-2 orders of magnitude larger openings at the other end. The former method is employed mostly in the case where single pores should be produced. The latter is more practical when multi-pore membranes are needed [45]. Using the advantages offered by this technology, we fabricated and employed in the present work a series of membranes of the same thickness, but with different sizes of highly asymmetric pores and with a small increment in the pore diameter on the selective side.

To study the stability of the interface in a membrane contactor, two systems were used that significantly (by an order of magnitude) differ in the value of the interfacial tension.

\section{Materials and Methods}

\subsection{Materials}

Distilled water with a specific conductance of less than $6 \mu \mathrm{Sm} / \mathrm{cm}$ was used as the model aqueous phase. Hexadecane (98\%) and 1-pentanol (99\%) (Component Reaktiv, Moscow, Russia) were used as model organic phases. Their properties are presented in Table 1. As one can see, the properties of 1-pentanol and hexadecane are pretty similar except for the interphase tension with water. In this case, the value for "water-1-pentanol" is by an order of magnitude lower than that for the "water-hexadecane" system. 
Table 1. Properties of liquids used for the membrane contactor [46].

\begin{tabular}{cccc}
\hline \multirow{2}{*}{ Property } & Aqueous Phase & \multicolumn{2}{c}{ Organic Phase } \\
\cline { 2 - 4 } & Water & Hexadecane & 1-Pentanol \\
\hline Molar mass, g/mole & 18 & 226.45 & 88.15 \\
Normal boiling point, ${ }^{\circ} \mathrm{C}$ & 100 & 286.8 & 137.9 \\
Viscosity at $25^{\circ} \mathrm{C}, \mathrm{mPa} \cdot \mathrm{s}$ & 0.895 & 3.08 & 3.36 \\
Surface tension at $25^{\circ} \mathrm{C}, \mathrm{mN} / \mathrm{m}$ & 71.98 & 27.15 & 25.3 \\
Interfacial tension of the water-liquid & - & 55.2 & 4.5 \\
interface at $25^{\circ} \mathrm{C}, \mathrm{mN} / \mathrm{m}$ & & & \\
\hline The value is presented at $2{ }^{\circ} \mathrm{C}$ & &
\end{tabular}

1 The value is presented at $22{ }^{\circ} \mathrm{C}$.

Distilled water and diiodomethane (99\%, Sigma-Aldrich, Schnelldorf, Germany) were used to evaluate the surface properties of the membranes. In addition, acetone (99.9\%, Chimmed, Moscow, Russia), distilled water, and hexadecane were used to investigate the effect of an asymmetric membrane's arrangement in the model mass transfer process from an organic phase to an aqueous phase. All the chemicals were used without further purification.

\subsection{Track-Etched Membranes}

PET membrane samples with pores of controlled geometry were obtained by the iontrack method. The pore system in these membranes is formed by irradiating a Hostaphan RNK film with a nominal thickness of $23 \pm 1 \mu \mathrm{m}$ with the $210 \mathrm{MeV}$ krypton ions from the U-400 cyclotron of the Flerov Laboratory of Nuclear Reactions, JINR. The polymer film with a width of $31 \mathrm{~cm}$ was transported across the scanned ion beam. The width of the irradiated area was $21 \mathrm{~cm}$. In order to minimize the effects of overlapping adjacent pores, the angles of entry of ions into the film were distributed in the interval $\pm 30^{\circ}$ to the surface normal.

Samples of A4 size were cut from the film and exposed to ultraviolet radiation with a power of $\sim 4 \mathrm{~W} / \mathrm{m}^{2}$ in the range of $280-315 \mathrm{~nm}$ on one side for $12 \mathrm{~h}$ to impart asymmetry. Chemical etching was carried out in a $3 \mathrm{M} \mathrm{NaOH}$ solution with $0.0125 \%$ Dowfax $2 \mathrm{~A} 1$ surfactant at $60{ }^{\circ} \mathrm{C}$ [45]. As a result, channels were formed with a diameter varying across the film thickness.

Small pieces were cut from the fabricated membrane samples and used for testing using SEM and other methods. The rest were employed in the experiments on extraction in the liquid-liquid contactor. The volume porosity of the membranes was determined by the formula:

$$
\Pi=100 \% \cdot \frac{m_{u n}-m_{i r}}{m_{u n}}
$$

where $m_{u n}$ and $m_{i r}$ are the masses of samples cut from unirradiated and irradiated areas, respectively. The sample size was $4 \times 4 \mathrm{~cm}$. The accuracy of weight measurements was $0.00001 \mathrm{~g}$.

The thickness of the membranes was measured using a Mitutoyo Litematic VL-50 instrument (accuracy: $\pm 0.1 \mu \mathrm{m}$ ).

\subsection{Membrane Characterization}

\subsubsection{Scanning Electron Microscopy}

The porous structure of the membranes was investigated by scanning electron microscopy (SEM). SEM was performed using the SU8020 microscope with a cold cathode (Hitachi, Japan). In order to improve the resolution and contrast of images, a thin layer of the gold-palladium alloy was deposited on the samples. For the determination of the surface pore diameter, all SEM images were recorded under identical conditions. The transverse size of pore openings was measured using the GATAN DIGITAL MICROGRAPH software. For each sample, 50-80 pores were analyzed. Cross-sections of the membranes were prepared after embrittlement with UV for about $100 \mathrm{~h}$ in air [47]. 


\subsubsection{Surface Properties of the Membranes}

The surface properties of the membranes were investigated by determining the contact angles for water and diiodomethane. The measurements were carried out on both sides of the track-etched membranes at room temperature $\left(23 \pm 2{ }^{\circ} \mathrm{C}\right)$.

Contact angle values were measured via the conventional sessile drop technique using the LK-1 goniometer. Each value was determined as a mean for five measurements. For image capture and digital processing of the drop images, the DropShape-software-provided Laplace-Young contact angle calculation was used. The measurement error was $2^{\circ}$.

The membrane surface energy value was determined according to the Owens-Wendt method [48]. The technique allows for the calculation of the surface energy value $\gamma$ as a sum of polar $\gamma^{p}$ and $\gamma^{d}$ dispersive components using two different liquids. The relation between the surface energy and the equilibrium contact angle of the liquid phase placed onto the solid phase is derived from the Fowkes equation [49]:

$$
\gamma_{l}(1+\cos \theta)=2\left(\gamma_{l}^{d} \gamma_{s}^{d}\right)^{1 / 2}+2\left(\gamma_{l}^{p} \gamma_{s}^{p}\right)^{1 / 2}
$$

where the superscripts $\langle d »$ and $\langle p »$ relate to the dispersive and polar components of the liquid surface energy $\left(\gamma_{l}\right)$ and the membrane surface $\left(\gamma_{s}\right)$, respectively.

Water and diiodomethane were used as test liquids, as the surface energy components of both liquids are well known and widely described in the literature [50,51].

\subsubsection{Dynamic Light Scattering}

The presence or absence of the mutual dispersion of liquids was controlled by the dynamic light scattering (DLS) method. For this, a 1-mL sample of each liquid was taken at the end of the hour-long experiment for study using a Malvern Zetasizer Nano ZS dynamic light scattering analyzer.

\subsection{Liquid-Liquid Membrane Contactor}

To study the mass transfer interface's stability during the operation of a liquid-liquid membrane contactor, a piece of experimental equipment with a flat-sheet membrane module was fabricated. The structural scheme and an external view of the piece of equipment are shown in Figure 1.

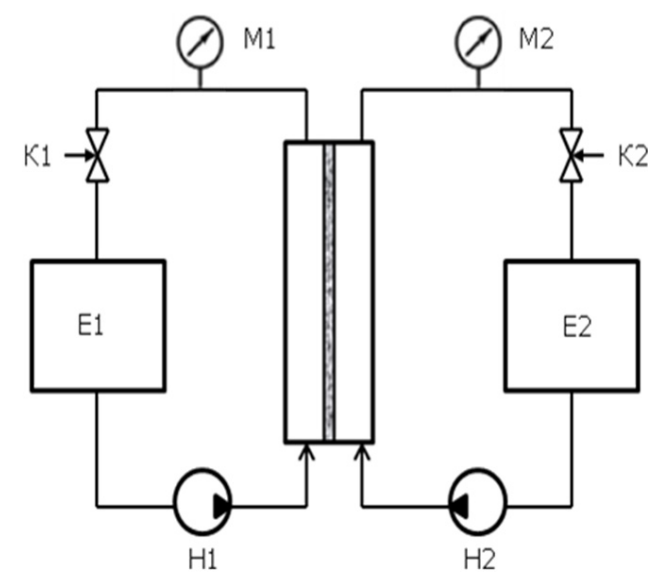

(A)

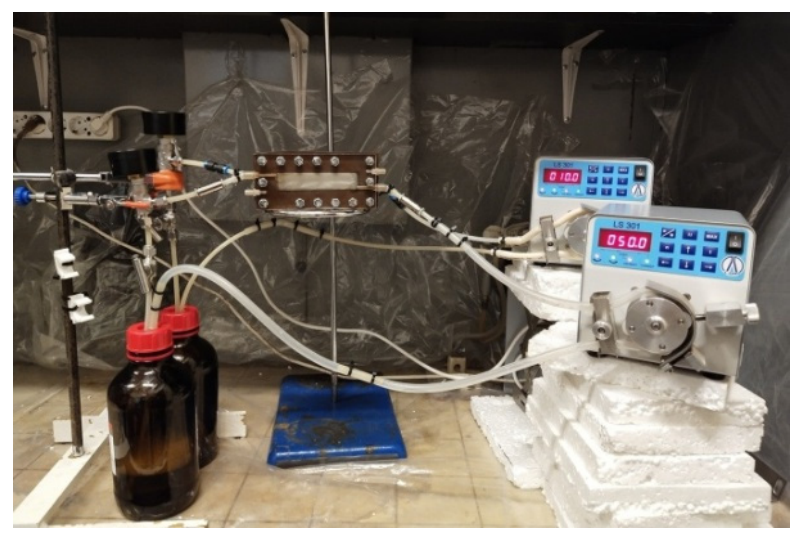

(B)

Figure 1. (A) Structural scheme and (B) external view of the setup for determining the stability of the interface in the liquid-liquid membrane contactor. M1, M2-manometers; K1, K2-fine adjustment valves; E1, E2-technological reservoirs containing water and organic liquid, respectively; $\mathrm{H} 1, \mathrm{H} 2$ - peristaltic pumps. 
The main working element was a flat-sheet membrane module whose liquid channels had a rectangular geometry. The active area of the membrane was $21.2 \mathrm{~cm}^{2}$. The vertical arrangement of the contactor avoids the formation of gas bubbles and stagnant zones during the liquid flow in the module's internal channels. The supply of liquids to the membrane contactor was carried out in the counter-current flow mode. The equipment allows for the variation and control of the liquid velocities and differences in their pressures. In order to study the presence or absence of mutual dispersion in the membrane contactor for a water-organic liquid pair, 1-pentanol and hexadecane with different surface energies and interfacial tensions of the water-organic systems were selected. Unless otherwise specified, the following mode was used in the work: the linear velocities of aqueous and organic phases are 2.4 and $0.5 \mathrm{~cm} / \mathrm{s}$, respectively; the organic liquid is at atmospheric pressure; and the water overpressure is $3 \mathrm{kPa}$.

In addition, studies were carried out to separate a small amount of pollutant from the organic liquid into the aqueous phase using a liquid-liquid membrane contactor with a different arrangement of the asymmetric track-etched membrane. For this purpose, a 1\% solution of acetone in hexadecane was used.

The concentration of solutions was determined using a Crystallux-4000M gas chromatograph. The chromatograph was equipped with an autosampler and a flame ionization detector. We used a Phenomenex Zebron ZB-FFAP capillary column (length, 50 m; diameter, $0.32 \mathrm{~mm}$; phase thickness, $0.50 \mu \mathrm{m})$. The data evaluation was done with NetChrom software.

\section{Results and Discussion}

\subsection{Track-Etched Membranes}

Figure 2 schematically shows a track-etched membrane with an asymmetric pore structure. For convenience, we designate the side of the track-etched membrane with a smaller diameter of the asymmetric pore as side $\mathbf{a}$, and the side with the larger pore diameter, respectively, as side $\mathbf{b}$.

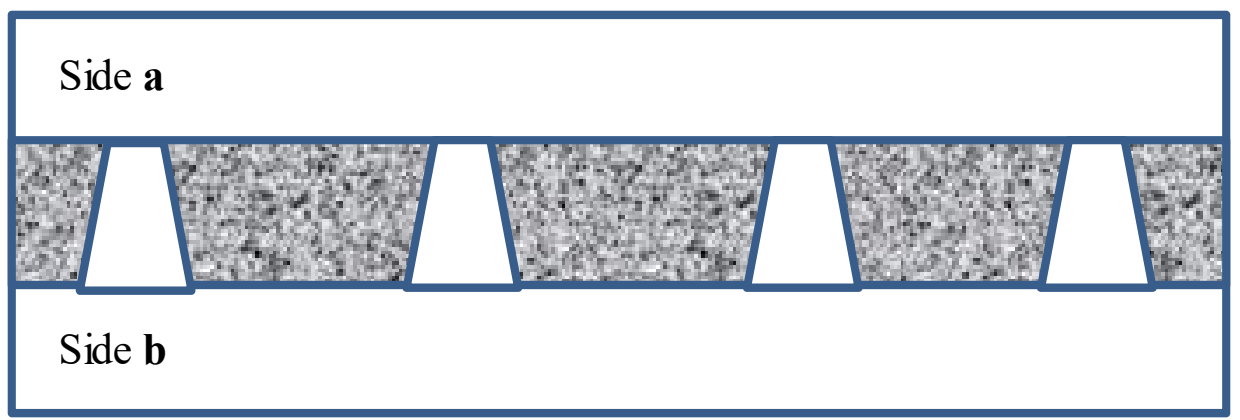

Figure 2. Schematic representation of the cross-section of asymmetric membranes.

\subsubsection{Characterization of Track-Etched Membranes Using SEM}

The porous structure of the track-etched membranes was investigated by scanning electron microscopy. SEM images of sides $\mathbf{a}$ and $\mathbf{b}$ for four studied membranes are presented in Figures 3 and 4 . The distributions of pore sizes for side a evaluated by using the GATAN software can also be seen in Figure 3.

Figure 5 shows a typical cross-section of the asymmetric track-etched membrane with high porosity, using the example of TEM-1. The top layer, the bottom layer, and a full cross-section are shown.

Depending on the etching time, the average pore diameter on side a varies in the range of 12-19 $\mathrm{nm}$. On the other side of the membrane, the entrances of individual pores merge and form a sponge-like structure because the apparent porosity is close to $100 \%$. The pores consist of a short funnel-shaped entrance on the UV-treated side, a long cylindrical part, and a short (ca. 1- $\mu \mathrm{m}$-long) conical tip. This configuration is typical of the pores produced by the procedure used (see, for instance, Figure 4 in [52], where images of individual pore 
channels are presented). A closer look at the SEM photos in Figure 5 also confirms the above geometry.
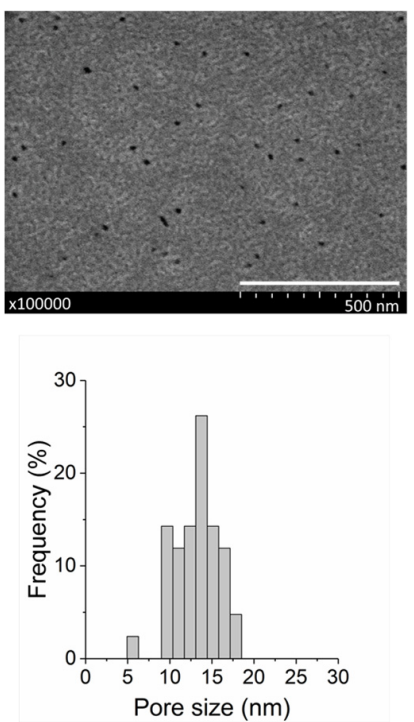

TEM-1
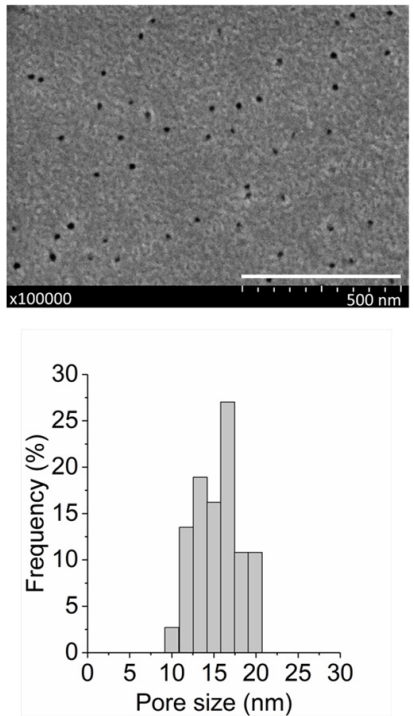

TEM-2
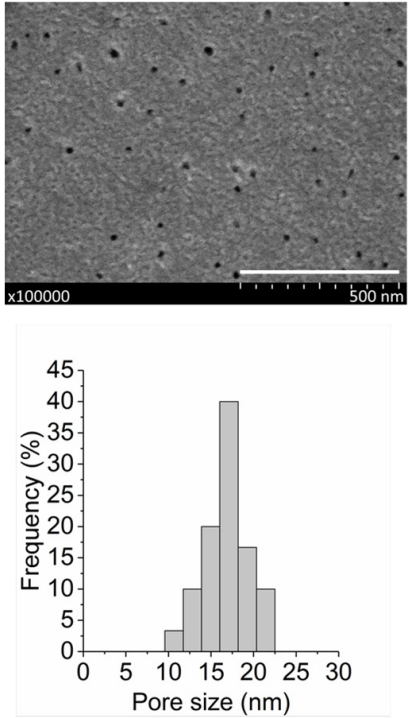

TEM-3
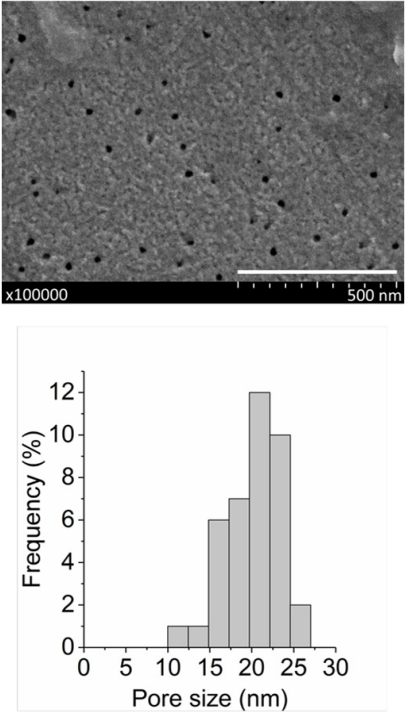

TEM-4

Figure 3. SEM images (top) and pore size distributions (bottom) of side a of membranes TEM-1, TEM-2, TEM-3 and TEM-4 (from the left to the right). Scale bar, $0.5 \mu \mathrm{m}$.

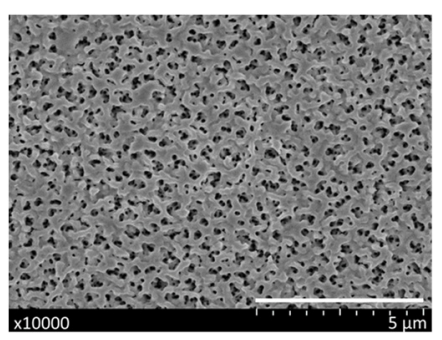

TEM-1

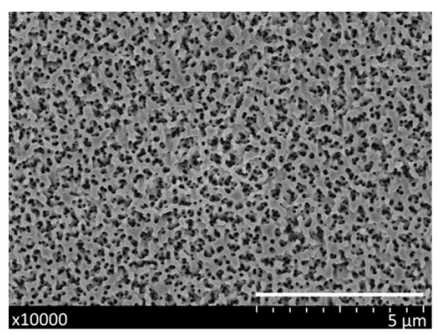

TEM-2

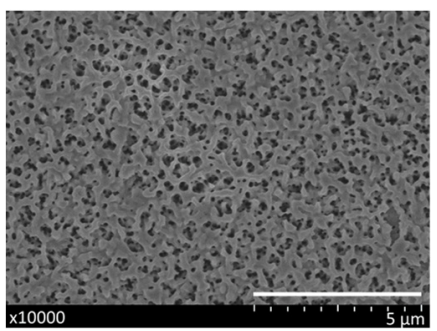

TEM-3

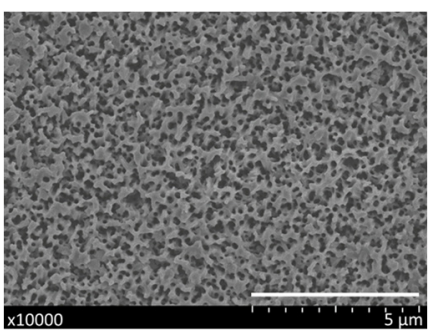

TEM-4

Figure 4. SEM images of side $\mathbf{b}$ of membranes TEM-1, TEM-2, TEM-3 and TEM-4 (from the left to the right). Scale bar, $5 \mu \mathrm{m}$.

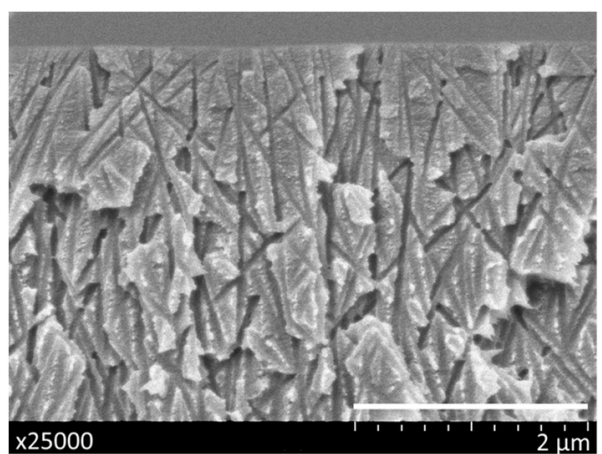

(A)

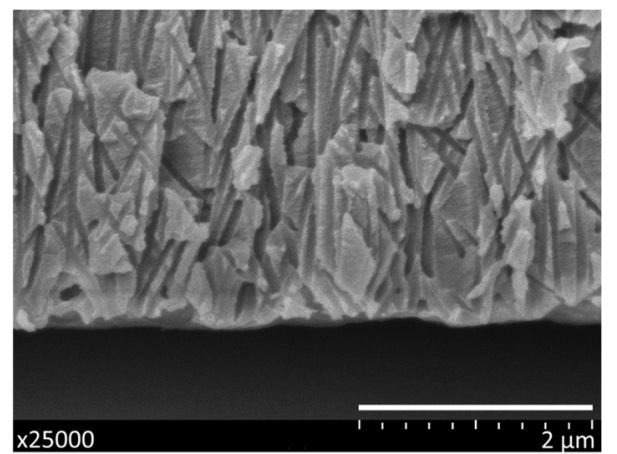

(B)

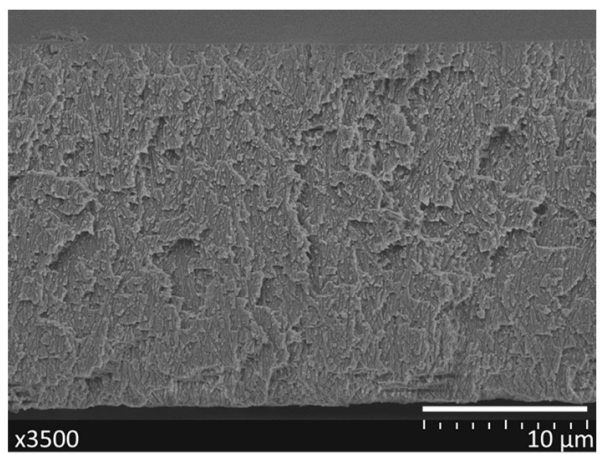

(C)

Figure 5. SEM images of a typical cross-section of TEM-1: the layers adjacent to sides $\mathbf{a}$ and $\mathbf{b}$ (images (A) and (B), respectively) and full thickness (C). Scale bars are shown in the frames.

Table 2 presents the structural characteristics of the studied membranes. It is important to emphasize that all four membranes possess practically the same thickness $(23 \pm 1 \mu \mathrm{m})$, have the same pore density $\left(4.5 \times 10^{9} \mathrm{~cm}^{-2}\right)$, and differ only in the pore size. It should be noted that commercial films do not have a constant thickness. The thickness of 23 microns 
is the nominal value. In reality, the thickness varies along and across the film in the roll at least within the range of $23 \pm 1 \mathrm{~mm}$, and sometimes even beyond this range. Moreover, the reader should take into account that we did not measure the thickness over the whole sample because the sample should have been clean and should not have been damaged by the gauge probe as a result of being excessively manipulated before use in the contactor. In fact, the deviations in the membrane's thickness did not actually have an observable influence on the membrane contactor system's performance. The average pore diameters on the selective side increased from approximately $12 \mathrm{~nm}$ to $19 \mathrm{~nm}$. These values are arbitrary to a certain extent because SEM cannot provide sufficiently accurate data in this range of dimensions. However, the sample size was large enough to make sure that the data confirmed a regular increase in the surface diameter with increasing etching time. All the SEM photos of membrane surfaces were taken under identical conditions, and, therefore, in the case of a bias, the bias would be similar for all four membrane samples.

Table 2. Structural characteristics of track-etched membranes.

\begin{tabular}{ccccc}
\hline Sample & $\begin{array}{c}\text { Time of Chemical } \\
\text { Etching, min }\end{array}$ & $\begin{array}{c}\text { Average Pore Diameter on } \\
\text { the Selective Side } \\
\text { Determined by SEM, nm }\end{array}$ & $\begin{array}{c}\text { Thickness, } \\
\boldsymbol{\mu m}\end{array}$ & $\begin{array}{c}\text { Volume Porosity, } \\
\%\end{array}$ \\
\hline TEM-1 & 3 & $12.5 \pm 0.3 *$ & 23.7 & 14 \\
TEM-2 & 3.5 & $14.7 \pm 0.4$ & 22.8 & 17 \\
TEM-3 & 4 & $15.7 \pm 0.5$ & 22.7 & 22 \\
TEM-4 & 4.5 & $19.0 \pm 0.5$ & 22.6 & 32 \\
\hline
\end{tabular}

* Standard deviation of the mean.

\subsubsection{Surface Properties of the Membranes}

Figure 6 shows the results of measuring the water and diiodomethane contact angles for the studied membranes. All samples of track-etched membranes are moderately hydrophilic with water wetting angles varying from $40^{\circ}$ to $67^{\circ}$. It is also possible to note the difference in the contact angles of different sides of the asymmetric membranes. For all the membranes, side $\mathbf{b}$, which was exposed to UV irradiation before etching, has increased hydrophilicity (a decrease in the water contact angle value).

Side a

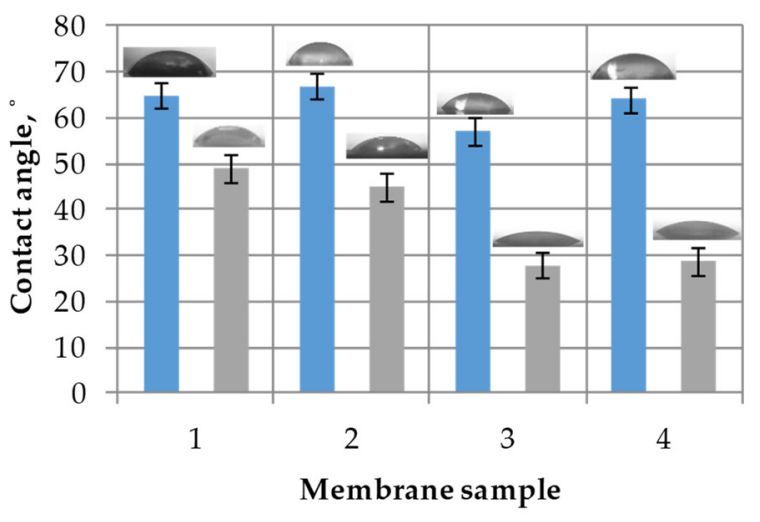

Side $b$

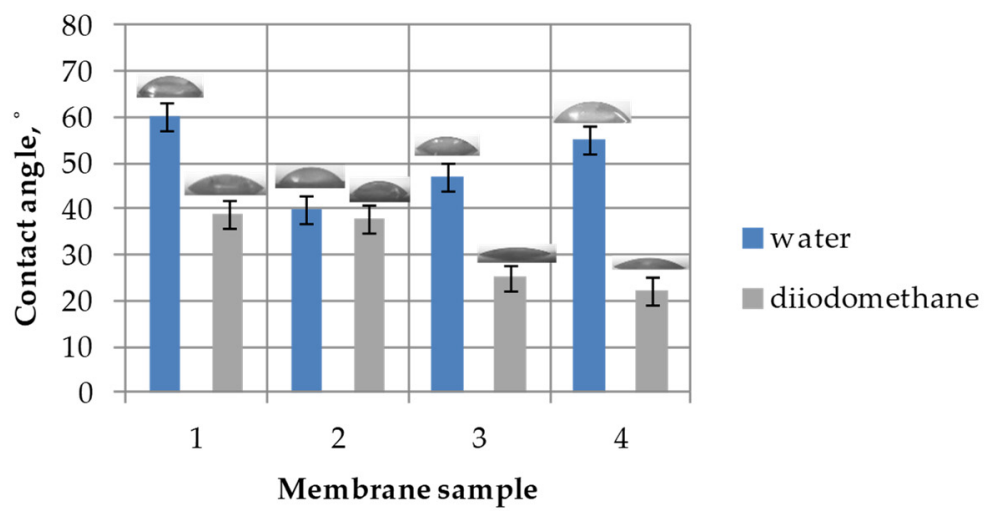

Figure 6. Water and diiodomethane contact angles: left—side $\mathbf{a}$; right—side $\mathbf{b}$.

The results of calculating the surface energy of the membranes are presented in Table 3. An increase in the hydrophilicity of side $\mathbf{b}$ with larger pores compared with side a with smaller pores is also expressed in the increase in the polar component of the surface energy, $\gamma^{p}$. Consequently, the total value of the surface energy also increases. It should be noted that the highest value of the polar component of the surface energy $\left(\gamma^{p}=31 \mathrm{~mJ} / \mathrm{m}^{2}\right)$ was obtained for side $\mathbf{b}$ of TEM-2. As a result, side $\mathbf{b}$ of TEM-2 has the highest surface 
energy of $59 \mathrm{~mJ} / \mathrm{m}^{2}$. A similar nonlinear effect of the sodium hydroxide etching procedure on the roughness and surface properties of the membranes was observed in [53].

Table 3. The surface energy of the membranes.

\begin{tabular}{ccccccc}
\hline & \multicolumn{5}{c}{ Surface Energy, $\mathbf{m J} / \mathbf{m}^{\mathbf{2}}$} \\
\cline { 2 - 7 } Sample & \multicolumn{7}{c}{ Side $\mathbf{b}$} \\
\cline { 2 - 7 } & $\gamma^{d}$ & $\gamma^{p}$ & $\gamma$ & $\gamma^{d}$ & $\gamma^{p}$ & $\gamma$ \\
\hline TEM-1 & 26 & 15 & 41 & 30 & 17 & 47 \\
TEM-2 & 28 & 13 & 41 & 28 & 31 & 59 \\
TEM-3 & 35 & 16 & 51 & 34 & 23 & 57 \\
TEM-4 & 35 & 12 & 47 & 36 & 17 & 53 \\
\hline
\end{tabular}

$\gamma^{d}$ is the polar component and $\gamma^{p}$ is the dispersive component of the surface energy $\gamma$.

The pentanol and hexadecane contact angles of the membranes were also measured. It was found that both sides of all membrane samples were thoroughly wetted with pentanol and hexadecane (the contact angles were less than $10^{\circ}$ ).

From the data on wettability, it can be concluded that the porous structure of the membranes will be filled with organic liquid when the membranes come into contact with aqueous and organic phases. In this regard, it is logical to maintain an overpressure of water when the membrane contactor is in operation.

\subsection{Liquid-Liquid Membrane Contactor System}

3.2.1. Influence of the Porous Structure of the Membrane on the Stability of the Phase Contact Interface

Table 4 shows the effect of the arrangement of the sides of the track-etched membranes in the "water-pentanol" and "water-hexadecane" systems under the following conditions: linear velocity of water $=2.4 \mathrm{~cm} / \mathrm{s}$; linear velocity of organic liquid $=0.5 \mathrm{~cm} / \mathrm{s} ; \Delta \mathrm{P}=3 \mathrm{kPa}$.

Table 4. Influence of the arrangement of the sides of the track-etched membranes.

\begin{tabular}{|c|c|c|c|c|}
\hline \multirow{4}{*}{ Sample } & & \multicolumn{2}{|c|}{ Interphase Surface Stability } & \multirow{4}{*}{$\begin{array}{l}\text { Side b - water } \\
\text { Side a - hexadecane }\end{array}$} \\
\hline & Side a - water & Side b - water & Side a - water & \\
\hline & 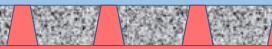 & Ans & 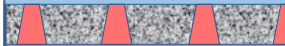 & \\
\hline & Side b - pentanol & Side a - pentanol & Side b - hexadecane & \\
\hline TEM-1 & - & + & + & + \\
\hline TEM-2 & - & + & + & + \\
\hline TEM-3 & - & - & - & - \\
\hline TEM-4 & - & - & - & - \\
\hline
\end{tabular}

For the "water-pentanol" pair, there is no stabilization of the interface for all studied membranes in the case of water supply from side a. It should be noted that this system is characterized by low interfacial tension $(4.5 \mathrm{mN} / \mathrm{m})$. With a change in the membrane arrangement in this system, the water supply from side $b$ leads to the stabilization of the contact surface of the phases for TEM- 1 and TEM-2 with pore sizes of 12.5 and $14.7 \mathrm{~nm}$, respectively. However, for TEM-3 and TEM-4, which have larger pore diameters, the stability of the interface is still absent, and mutual mixing of phases was observed.

A somewhat different picture was observed for the "water-hexadecane" system with high interfacial tension $(55.2 \mathrm{mN} / \mathrm{m})$. The liquid-liquid interface for TEM-1 and TEM-2 with pore sizes of 12.5 and $14.7 \mathrm{~nm}$, respectively, is stable regardless of the membrane arrangement towards water or hexadecane. However, for TEM-3 and TEM-4, which have larger pore sizes (15.7 and $19.0 \mathrm{~nm}$, respectively), the stability of the interface was not observed, as in the case of the "water-pentanol" system. 
Thus, a preliminary conclusion can be drawn that the water supply from side $\mathbf{b}$ with the larger asymmetric pore size is preferable for the stable operation of the liquid-liquid membrane contactor, regardless of the considered water-organic system. In addition, it can be concluded that the pore size of the TEM- 3 and TEM- 4 samples exceeds the required diameter (approximately $15 \mathrm{~nm}$ ) for the implementation of stable operation of the contactor. In this regard, TEM-1 and TEM-2 were further investigated.

From our point of view, this behavior can be explained by the existence of a threshold value for a specific combination of membrane pore size and liquid-liquid interfacial tension. This value is higher than that obtained for TEM-2 but lower than that obtained for TEM-3. The exceedance of this value in the TEM- 3 case and in the TEM-4 case results in the presence of mutual dispersion of the "water-hexadecane" pair as stated in Table 4. The second possible explanation for this case is the difference in the surface energy of the studied membranes.

\subsubsection{Influence of a Drop in Pressure between Phases on the Interphase Stability}

Excessive water pressure is necessary to control the organic phase's flow through the membrane's pores, which thoroughly wets both its surfaces. Table 5 shows the results of the experiment on the interphase stability for the "water-hexadecane" system within contactors based on TEM-1 and TEM-2. The excessive water pressure was varied within the range of 3-13 $\mathrm{kPa}$. The following two conclusions follow from the data shown in Table 5. First, the stability of the contactor is higher for both studied membranes in the case of water supply from side $\mathbf{b}$, that is, from the side whose asymmetric pores have a larger diameter. This result confirms the conclusion drawn in the previous section. Second, TEM-2 is more stable than TEM-1. This result contradicts the fact that the pore diameter of TEM-2 $(14.7 \mathrm{~nm})$ is larger than the pore diameter of TEM-1 $(12.5 \mathrm{~nm})$. The highest value of the polar component of the surface energy $\left(31 \mathrm{~mJ} / \mathrm{m}^{2}\right)$ and the value of the surface energy $\left(59 \mathrm{~mJ} / \mathrm{m}^{2}\right.$ ) of side $\mathbf{b}$ (Table 3) may be possible explanations for the increased stability of TEM-2.

Table 5. Influence of water overpressure on the interphase stability of the "water-hexadecane" system for TEM-1 and TEM-2.

\begin{tabular}{|c|c|c|c|c|}
\hline \multirow{5}{*}{$\begin{array}{c}\text { Water Overpressure, } \\
\text { kPa }\end{array}$} & \multicolumn{4}{|c|}{ Interphase Surface Stability } \\
\hline & \multicolumn{2}{|c|}{ TEM-1 } & \multicolumn{2}{|c|}{ TEM-2 } \\
\hline & Side a - water & Side b - water & Side a - water & Side b - water \\
\hline & (3) & 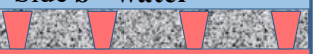 & in & 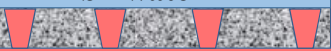 \\
\hline & Side b - hexadecane & Side a - hexadecane & Side b - hexadecane & Side a - hexadecane \\
\hline 3 & + & + & + & + \\
\hline 5 & - & + & + & + \\
\hline 7 & - & + & - & + \\
\hline 10 & $\mathrm{n} / \mathrm{a}$ & - & - & + \\
\hline 13 & $\mathrm{n} / \mathrm{a}$ & $\mathrm{n} / \mathrm{a}$ & $\mathrm{n} / \mathrm{a}$ & - \\
\hline
\end{tabular}

3.2.3. Influence of the Parameters of the Membrane-Contactor System on the Stability of the Liquid-Liquid Interface

The results of varying the liquid velocities on the mutual dispersion of phases for TEM-2 and the "water-hexadecane" system are presented in Table 6. In all cases, $\Delta \mathrm{P}=3 \mathrm{kPa}$. TEM-2 and the "water-hexadecane" system were chosen because they were found to be the most stable.

As can be seen, the stability of the liquid-liquid interface is more sensitive to variations in the water's velocity than to variations in the organic liquid's velocity. As shown in [54], the system's resistance caused by the water flow is the determining factor. When the water's velocity increases to a specific limit, the shear force of the water phase flow prevails over the interfacial tension, and the drops begin to detach. Additionally, the drop size 
decreases with an increase in the water's velocity, which also agrees with the data given in [54].

Table 6. Effect of operational parameters of the membrane contactor on the liquid-liquid interface stability for TEM-2.

\begin{tabular}{|c|c|c|c|c|c|c|c|}
\hline \multicolumn{4}{|c|}{$\begin{array}{l}\text { Side } a \text {-Hexadecane } \\
\text { Side } b \text {-Water }\end{array}$} & \multicolumn{4}{|c|}{$\begin{array}{c}\text { Side } a-\text { Water } \\
\text { Side } b-\text { Hexadecane }\end{array}$} \\
\hline \multicolumn{2}{|c|}{$\begin{array}{l}\text { The linear velocity of water = } \\
2.4 \mathrm{~cm} / \mathrm{s} \text {; the linear velocity of } \\
\text { hexadecane varies }\end{array}$} & \multicolumn{2}{|c|}{$\begin{array}{l}\text { The linear velocity of water varies; } \\
\text { the linear velocity of hexadecane } \\
=2.6 \mathrm{~cm} / \mathrm{s}\end{array}$} & \multicolumn{2}{|c|}{$\begin{array}{c}\text { The linear velocity of water = } \\
2.4 \mathrm{~cm} / \mathrm{s} \text {; the linear velocity of } \\
\text { hexadecane varies }\end{array}$} & \multicolumn{2}{|c|}{$\begin{array}{l}\text { The linear velocity of water varies; } \\
\text { the linear velocity of hexadecane } \\
=2.6 \mathrm{~cm} / \mathrm{s}\end{array}$} \\
\hline $\begin{array}{l}\text { The linear } \\
\text { velocity of } \\
\text { hexadecane }\end{array}$ & DLS & $\begin{array}{c}\text { The linear } \\
\text { velocity of } \\
\text { hexadecane }\end{array}$ & DLS & $\begin{array}{l}\text { The linear } \\
\text { velocity of } \\
\text { hexadecane }\end{array}$ & DLS & $\begin{array}{c}\text { The linear } \\
\text { velocity of } \\
\text { hexadecane }\end{array}$ & DLS \\
\hline 1.6 & - & 1.6 & - & 1.6 & - & 1.6 & - \\
\hline 1.9 & - & 1.9 & - & 1.9 & - & 1.9 & - \\
\hline 3 & - & 3 & - & 3 & - & 3 & - \\
\hline 3.3 & - & 3.3 & - & 3.3 & - & 3.3 & - \\
\hline 3.9 & $\begin{array}{l}\text { hexadecane } \\
\text { drops }(176 \mathrm{~nm}) \\
\text { in water }\end{array}$ & 3.9 & $\begin{array}{l}\text { hexadecane } \\
\text { drops }(176 \mathrm{~nm}) \\
\text { in water }\end{array}$ & 3.9 & $\begin{array}{l}\text { hexadecane } \\
\text { drops }(176 \mathrm{~nm}) \\
\text { in water }\end{array}$ & 3.9 & $\begin{array}{l}\text { hexadecane } \\
\text { drops }(176 \mathrm{~nm}) \\
\text { in water }\end{array}$ \\
\hline
\end{tabular}

\subsubsection{Discussion of Obtained Results}

Let us consider the formation of a meniscus in a water-membrane-organic system. Figure 7 shows the scheme of the conical channel and possible profiles of menisci of the organic component at the boundary with water in the case of water supply from the side with larger and smaller channel radii in the equilibrium state, subject to compensation for capillary pressure. Here, $\theta$ is the contact angle, $\alpha$ is the cone angle, $R_{0}$ is the radius of the channel of side $\mathbf{a}$ (see Table 2), and $R_{1}$ is the radius of the channel of side $\mathbf{b}$. Estimates show that the angle value is several degrees for the characteristic radius $R_{1}$ on the order of several nanometers and for a membrane thickness of $23 \mu \mathrm{m}$ (see Table 2). The breakdown and penetration of organic particles into the water when the water's location is on side a or side $\mathbf{b}$ will probably occur after an increase in pressure from the organic side, leading to the disappearance of the meniscus. A further increase in pressure can lead to the formation of a meniscus above the membrane from the water side and the separation of organic particles by the water's flow.

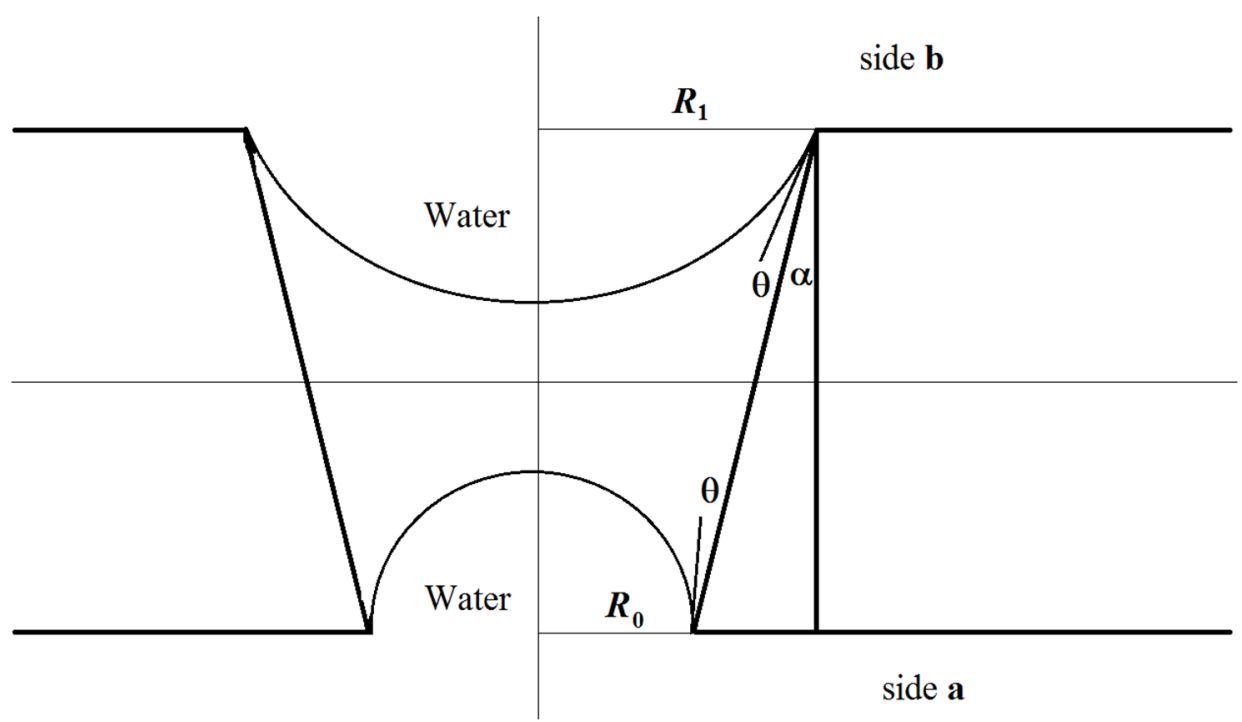

Figure 7. Scheme of the cone channel and possible profiles of the menisci of the organic component at the boundary with water.

However, for the case with water on side a, the value $\Delta p \sim \frac{2 \gamma \cos \theta}{R_{0}}$ will be on the order of tens of atmospheres and cannot be compensated for by water pressure on side $\mathbf{a}$. 
The most probable scenario for developing the interaction of the water-insoluble organic liquid with the surface of the material and water is shown in Figure 8.

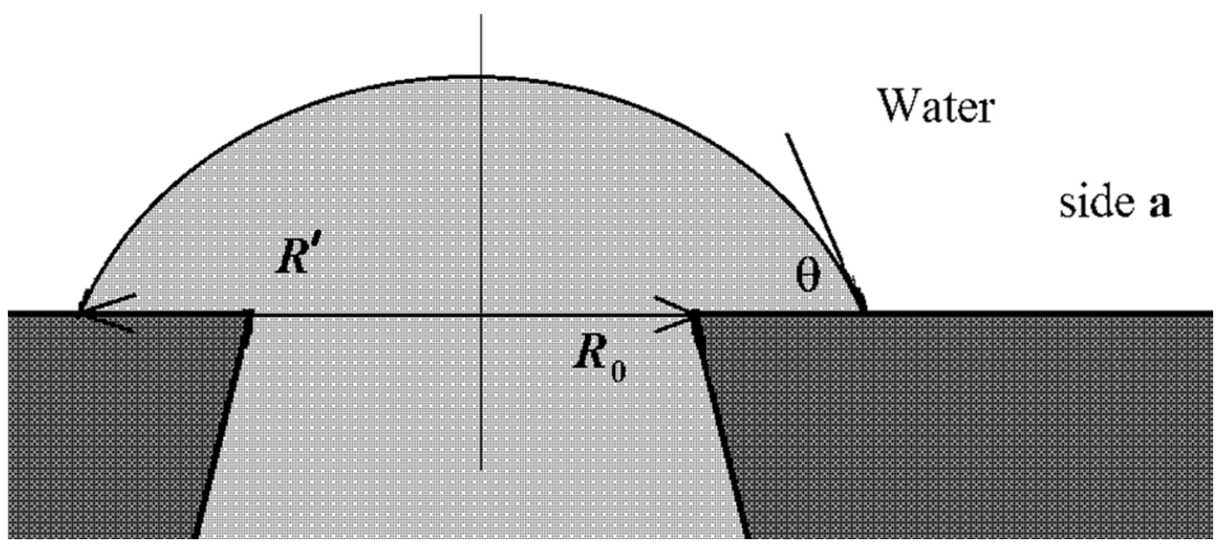

Figure 8. Scheme of the interaction of the water-insoluble organic liquid with the surface of the material and water on side $\mathbf{a}$.

The organic liquid partially spreads over the membrane's surface until an equilibrium is established between the energy of formation of the "organic component-membrane" surface and the energy of formation of the "water-organic component" surface:

$$
\gamma_{m o} \Delta S_{m o}=\gamma_{w o} \Delta S_{w o}
$$

where $\gamma_{m o}$ is the energy of formation of the "membrane-organic liquid" surface, $\Delta S_{m o}$ is the surface area of the contact between the membrane and the organic liquid, $\gamma_{w o}$ is the energy of formation of the "water-organic liquid" surface, and $\Delta S_{w o}$ is the surface area of the contact between the water and the organic liquid. Thus, the membrane surface on side a will already contain an insoluble organic liquid, which explains the lower transmembrane pressure required to detach this component from the surface and, accordingly, the lower water velocity.

In the case where the water phase's location is on side $\mathbf{b}$, the rise of the organic liquid due to the formation of an energetically favorable "organic liquid-membrane" surface will be compensated for by an increase in the energetically unfavorable "water-organic liquid" surface (3). In this case, the scheme shown in Figure 9 will most likely be implemented.

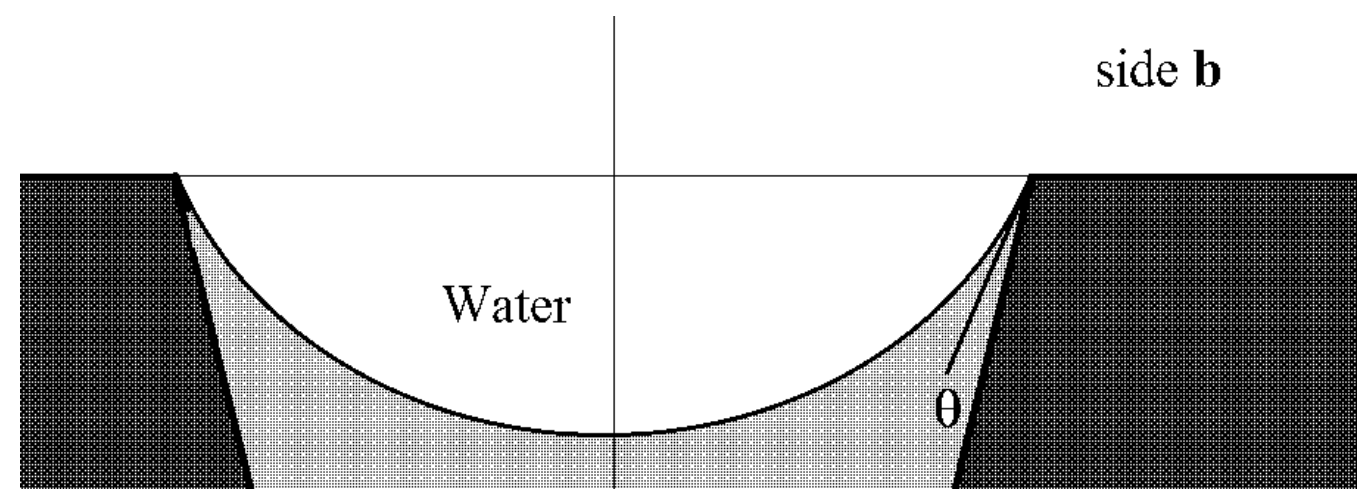

Figure 9. Scheme of the interaction of the water-insoluble organic liquid with the surface of the material and water on side $\mathbf{b}$.

It should be pointed out that the surface of the membrane on side $\mathbf{b}$ has a crumbling, spongy structure (see Figure 4). Consequently, the near-surface layer of the membrane will predominantly contain water rather than the organic component. 
Within the framework of such physical concepts, it is also possible to explain the difference in results for different organic components (hexadecane and 1-pentanol). In the case of 1-pentanol, the value $\gamma_{w o}$ is several times lower than that for hexadecane (see Table 1). This means that the formation of an energetically unfavorable "water-organic liquid" surface in this case limits the spread of the organic component over the membrane surface to a lesser extent and, therefore, the probability of the organic liquid's penetration into the water increases.

In practice, the obtained track-etched membranes might be promising, e.g., for a process such as membrane emulsification (for example, for pharmaceuticals). This is a process in which two immiscible phases are brought into contact in a membrane module, while one phase is forced into the other through the membrane pores, and as a result an emulsion is formed in the second phase. Obviously, in this case, one of the primary roles in the resulting properties of the derived emulsion is played by the membrane's porous structure. The more monomodal the pore distribution, the narrower the size distribution of the emulsion drops. The lower the concentration and the more uniform the distribution of pores on the surface, the lower the probability that drops will merge at the mouths of two adjacent pores, and, again, the narrower the drop size distribution (see, for example, $[55,56])$.

\subsection{Extraction of Acetone from the Organic Phase to the Aqueous Phase in the Membrane Contactor}

Experiments on the extraction of a small amount of pollutant from the organic phase to water using the developed liquid-liquid membrane contactor with different arrangements of the asymmetric track-etched membrane were carried out. It is known that oxygenates, such as carboxylic acids, aldehydes/ketones, and alcohols, are often present in less than $10 \mathrm{wt}$ \% concentrations in the apolar organic solvents from which they are to be recovered $[57,58]$. In this work, the extraction of acetone from its $1 \%$ solution in hexadecane to the aqueous phase was tested in the developed liquid-liquid membrane contactor using the asymmetric membrane TEM-1. Figure 10 shows a decrease in the acetone content in the organic phase of up to $50 \%$ regarding the initial concentration. However, the arrangement of the membrane's sides does not actually affect the efficiency of the transfer. Therefore, it is better to realize the mass transfer process in the membrane contactor extraction system with the water at side a. This case allows us to apply a larger pressure difference between the phases at the same efficiencies of target component extraction.
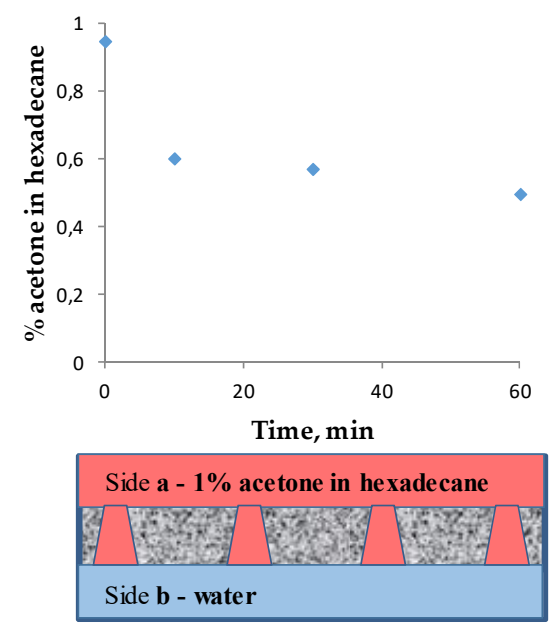
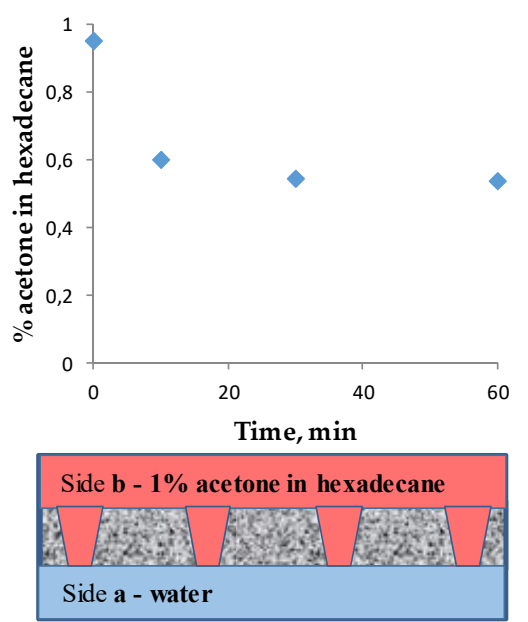

Figure 10. Decrease in the acetone content in the organic phase in the liquid-liquid membrane contactor with different membrane arrangements.

Thus, the liquid-liquid contactor based on track-etched membranes distinctly allows for the extraction of unwanted contaminants from the organic phase to the aqueous phase. 


\section{Conclusions}

In this work, track-etched PET membranes with highly asymmetric pores were prepared. The pore sizes varied from $12.5 \mathrm{~nm}$ to $19 \mathrm{~nm}$, while the values on the other side of the membrane were an order of magnitude higher. The data on the surface properties indicate that the membranes are lyophilic, i.e., wetted with both water and organic phases. The obtained membranes demonstrate surface energy values in the range of $41-59 \mathrm{~mJ} / \mathrm{m}^{2}$. It was established that the asymmetry of the porous structure has an influence on the tolerable parameters of liquid-liquid membrane contactor. For example, water supply from the side with a larger pore size is preferable for the stable operation of the liquid-liquid contactor. Additionally, in the case of asymmetric membranes it is possible to expand the range of values of the drop in pressure between the phases by at least two times (from 5 to $10 \mathrm{kPa}$ ), which does not lead to mutual dispersion of the liquids, while in symmetric membranes, a strict value of the drop in pressure should be maintained.

The stability of the liquid-liquid interface increases with decreasing pore size. At the same time, the organization of the process in which water is supplied on the side with larger pore sizes is preferable for implementing a membrane contactor system since it leads to a more stable liquid-liquid interface, particularly for a system with lower interfacial tension.

The stability of the liquid-liquid interface in the membrane contactor is more sensitive to variations in the water velocity than to variations in the organic liquid velocity. In this case, with an increase in the water flow rate, the drop size decreases.

Finally, we have demonstrated that the liquid-liquid contactor based on the fabricated track-etched membranes makes it possible to efficiently extract pollutants from the organic phase into the aqueous phase using a $1 \%$ solution of acetone in hexadecane as a model system.

Author Contributions: Conceptualization, S.B.; methodology, S.B. and P.A.; investigation, M.K., O.K. and R.A.; data analysis, S.B., A.B. and M.K.; writing—original draft preparation, M.K.; writingreview and editing, S.B., P.A. and A.B. All authors have read and agreed to the published version of the manuscript.

Funding: The reported study was funded by RFBR, project number 20-38-70088.

Institutional Review Board Statement: Not applicable.

Informed Consent Statement: Not applicable.

Data Availability Statement: The data presented in this study are available on request from the corresponding author.

Acknowledgments: S.B., O.K., M.K. and P.A. acknowledge the support of RFBR. The authors thank O.L. Orelovich and N.E. Lizunov for the SEM examination of membrane samples. The authors thank the reviewers for critically reading the manuscript and their suggestions, which substantially improved the manuscript.

Conflicts of Interest: The authors declare no conflict of interest.

\section{References}

1. Baker, R.W. Membrane Technology and Applications, 3rd ed.; John Wiley and Sons: Hoboken, NJ, USA, 2012; 576p.

2. Russian Membrane Society. Terminology. Membr. Membr. Technol. 2013, 3, 74-82. [CrossRef]

3. Zhao, S.; Feron, P.H.M.; Deng, L.; Favre, E.; Chabanon, E.; Yan, S.; Hou, J.; Chen, V.; Qi, H. Status and progress of membrane contactors in post-combustion carbon capture: A state-of-the-art review of new developments. J. Membr. Sci. 2016, 511, 180-206. [CrossRef]

4. Obstals, F.; Vorobii, M.; Riedel, T.; de los Santos Pereira, A.; Bruns, M.; Singh, S.; Rodriguez-Emmenegger, C. Improving Hemocompatibility of Membranes for Extracorporeal Membrane Oxygenators by Grafting Nonthrombogenic Polymer Brushes. Macromol. Biosci. 2018, 18, 1700359. [CrossRef]

5. Zheng, Z.; Wang, W.; Huang, X.; Fan, W.; Li, L. Surface modification of polysulfone hollow fiber membrane for extracorporeal membrane oxygenator using low-temperature plasma treatment. Plasma Proc. Polym. 2018, 15, 1700122. [CrossRef]

6. Li, S.; Pyrzynski, T.J.; Klinghoffer, N.B.; Tamale, T.; Zhong, Y.; Aderhold, J.L.; Zhou, S.J.; Meyer, H.S.; Ding, Y.; Bikson, B. Scale-up of PEEK hollow fiber membrane contactor for post-combustion $\mathrm{CO}_{2}$ capture. J. Membr. Sci. 2017, 527, 92-101. [CrossRef] 
7. Tantikhajorngosol, P.; Laosiripojana, N.; Jiraratananon, R.; Assabumrungrat, S. Physical absorption of $\mathrm{CO}_{2}$ and $\mathrm{H}_{2} \mathrm{~S}$ from synthetic biogas at elevated pressures using hollow fiber membrane contactors: The effects of Henry's constants and gas diffusivities. Int. J. Heat Mass Transf. 2019, 128, 1136-1148. [CrossRef]

8. Henares, M.; Ferrero, P.; San-Valero, P.; Martínez-Soria, V.; Izquierdo, M. Performance of a polypropylene membrane contactor for the recovery of dissolved methane from anaerobic effluents: Mass transfer evaluation, long-term operation and cleaning strategies. J. Membr. Sci. 2018, 563, 926-937. [CrossRef]

9. Martić, I.; Maslarević, A.; Mladenović, S.; Lukić, U.; Budimir, S. Water deoxygenation using hollow fiber membrane module with nitrogen as inert gas. Desalin. Water Treat. 2015, 54, 1563-1567. [CrossRef]

10. Ghasem, N.; Al-Marzouqi, M.; Ismail, Z. Gas-liquid membrane contactor for ethylene/ethane separation by aqueous silver nitrate solution. Sep. Purif. Technol. 2014, 127, 140-148. [CrossRef]

11. Xu, Y.; Goh, K.; Wang, R.; Bae, T.-H. A review on polymer-based membranes for gas-liquid membrane contacting processes: Current challenges and future direction. Sep. Purif. Technol. 2019, 229, 115791. [CrossRef]

12. Goh, P.S.; Naim, R.; Rahbari-Sisakht, M.; Ismail, A.F. Modification of membrane hydrophobicity in membrane contactors for environmental remediation. Sep. Purif. Technol. 2019, 227, 115721. [CrossRef]

13. Bazhenov, S.; Bildyukevich, A.; Volkov, A. Gas-liquid hollow fiber membrane contactors for different applications. Fibers 2018, 6, 76. [CrossRef]

14. Bazhenov, S.D.; Lyubimova, E.S. Gas-liquid membrane contactors for carbon dioxide capture from gaseous streams. Pet. Chem. 2016, 56, 889-914. [CrossRef]

15. Winter, D.; Koschikowski, J.; Gross, F.; Maucher, D.; Düver, D.; Jositz, M.; Mann, T.; Hagedorn, A. Comparative analysis of full-scale membrane distillation contactors-Methods and modules. J. Membr. Sci. 2017, 524, 758-771. [CrossRef]

16. Darestani, M.; Haigh, V.; Couperthwaite, S.J.; Millar, G.J.; Nghiem, L.D. Hollow fibre membrane contactors for ammonia recovery: Current status and future developments. J. Environ. Chem. Eng. 2017, 5, 1349-1359. [CrossRef]

17. Aligwe, P.A.; Sirkar, K.K.; Canlas, C.J. Hollow fiber gas membrane-based removal and recovery of ammonia from water in three different scales and types of modules. Sep. Purif. Technol. 2019, 224, 580-590. [CrossRef]

18. Xu, X.; Martin, G.J.; Kentish, S.E. Enhanced $\mathrm{CO}_{2}$ bio-utilization with a liquid-liquid membrane contactor in a bench-scale microalgae raceway pond. J. $\mathrm{CO}_{2}$ Util. 2019, 34, 207-214. [CrossRef]

19. Rehman, W.U.; Muhammad, A.; Khan, Q.A.; Younas, M.; Rezakazemi, M. Pomegranate juice concentration using osmotic distillation with membrane contactor. Sep. Purif. Technol. 2019, 224, 481-489. [CrossRef]

20. Pabby, A.K.; Sastre, A.M. State-of-the-art review on hollow fibre contactor technology and membrane-based extraction processes. J. Membr. Sci. 2013, 430, 263-303. [CrossRef]

21. Kiani, A.; Bhave, R.R.; Sirkar, K.K. Solvent extraction with immobilized interfaces in a microporous hydrophobic membrane. J. Membr. Sci. 1984, 20, 125-145. [CrossRef]

22. D'elia, N.A.; Dahuron, L.; Cussler, E.L. Liquid-liquid extractions with microporous hollow fibers. J. Membr. Sci. 1986, 29 , 309-319. [CrossRef]

23. Song, J.; Huang, T.; Qiu, H.; Niu, X.; Li, X.M.; Xie, Y.; He, T. A critical review on membrane extraction with improved stability: Potential application for recycling metals from city mine. Desalination 2018, 440, 18-38. [CrossRef]

24. De Souza Moraes, L.; de Araujo Kronemberger, F.; Ferraz, H.C.; Habert, A.C. Liquid-liquid extraction of succinic acid using a hollow fiber membrane contactor. J. Ind. Eng. Chem. 2015, 21, 206-211. [CrossRef]

25. Moreno, T.; Tallon, S.J.; Catchpole, O.J. Supercritical $\mathrm{CO}_{2}$ extraction of 1-butanol and acetone from aqueous solutions using a hollow-fiber membrane contactor. Chem. Eng. Technol. 2014, 37, 1861-1872. [CrossRef]

26. Shojaee Nasirabadi, P.; Saljoughi, E.; Mousavi, S.M. Membrane processes used for removal of pharmaceuticals, hormones, endocrine disruptors and their metabolites from wastewaters: A review. Desalin. Water Treat. 2016, 57, 24146-24175. [CrossRef]

27. Hylton, K.; Sangwan, M.; Mitra, S. Microscale membrane extraction of diverse antibiotics from water. Anal. Chim. Acta 2009, 653, 116-120. [CrossRef]

28. Yahaya, G.O.; Hamad, F.; Bahamdan, A.; Tammana, V.V.; Hamad, E.Z. Supported ionic liquid membrane and liquid-liquid extraction using membrane for removal of sulfur compounds from diesel/crude oil. Fuel Proc. Technol. 2013, 113, 123-129. [CrossRef]

29. Ferreira, A.R.; Neves, L.A.; Ribeiro, J.C.; Lopes, F.M.; Coutinho, J.A.; Coelhoso, I.M.; Crespo, J.G. Thiols' extraction from "jet-fuel” assisted by ionic liquids in hollow fibre membrane contactors. J. Membr. Sci. 2015, 477, 66-73. [CrossRef]

30. Amelio, A.; Loise, L.; Azhandeh, R.; Darvishmanesh, S.; Calabró, V.; Degrève, J.; Luis, P.; Van der Bruggen, B. Purification of biodiesel using a membrane contactor: Liquid-liquid extraction. Fuel Proc. Technol. 2016, 142, 352-360. [CrossRef]

31. Prasad, R.; Kiani, A.; Bhave, R.R.; Sirkar, K.K. Further studies on solvent extraction with immobilized interfaces in a microporous hydrophobic membrane. J. Membr. Sci. 1986, 26, 79-97. [CrossRef]

32. Prasad, R.; Sirkar, K.K. Microporous Membrane Solvent Extraction. Sep. Sci. Technol. 1987, 22, 619-640. [CrossRef]

33. Prasad, R.; Sirkar, K.K. Solvent extraction with microporous hydrophilic and composite membranes. AIChE J. 1987, 33, 1057-1066. [CrossRef]

34. Feng, S.; Zhong, Z.; Wang, Y.; Xing, W.; Drioli, E. Progress and perspectives in PTFE membrane: Preparation, modification, and applications. J. Membr. Sci. 2018, 549, 332-349. [CrossRef] 
35. Himma, N.F.; Anisah, S.; Prasetya, N.; Wenten, I.G. Advances in preparation, modification, and application of polypropylene membrane. J. Polym. Eng. 2016, 36, 329-362. [CrossRef]

36. Guillen, G.R.; Pan, Y.; Li, M.; Hoek, E.M. Preparation and Characterization of Membranes Formed by Nonsolvent Induced Phase Separation: A Review. Ind. Eng. Chem. Res. 2011, 50, 3798-3817. [CrossRef]

37. Thakur, V.K.; Voicu, S.I. Recent advances in cellulose and chitosan based membranes for water purification: A concise review. Carbohydr. Polym. 2016, 146, 148-165. [CrossRef]

38. Apel, P.Y. Fabrication of functional micro- and nanoporous materials from polymers modified by swift heavy ions. Radiat. Phys. Chem. 2019, 159, 25-34. [CrossRef]

39. Yeszhanov, A.B.; Korolkov, I.V.; Dosmagambetova, S.S.; Zdorovets, M.V.; Güven, O. Recent progress in the membrane distillation and impact of track-etched membranes. Polymer 2021, 13, 2520. [CrossRef]

40. Kislyi, A.G.; Butylskii, D.Y.; Mareev, S.A.; Nikonenko, V.V. Model of Competitive Ion Transfer in an Electro-Baromembrane System with Track-Etched Membrane. Membr. Membr. Technol. 2021, 3, 131-138. [CrossRef]

41. Butylskii, D.Y.; Pismenskaya, N.D.; Apel, P.Y.; Sabbatovskiy, K.G.; Nikonenko, V.V. Highly selective separation of singly charged cations by countercurrent electromigration with a track-etched membrane. J. Membr. Sci. 2021, 635, 119449. [CrossRef]

42. Armstrong, J.A.; Bernal, E.E.L.; Yaroshchuk, A.; Bruening, M.L. Separation of Ions Using Polyelectrolyte-Modified Nanoporous Track-Etched Membranes. Langmuir 2013, 29, 10287-10296. [CrossRef] [PubMed]

43. Tang, C.; Yaroshchuk, A.; Bruening, M.L. Flow through negatively charged, nanoporous membranes separates $\mathrm{Li}^{+}$and $\mathrm{K}^{+}$due to induced electromigration. Chem. Commun. 2020, 56, 10954-10957. [CrossRef] [PubMed]

44. Apel, P.Y.; Korchev, Y.E.; Siwy, Z.; Spohr, R.; Yoshida, M. Diode-like single-ion track membrane prepared by electro-stopping. Nucl. Instrum. Meth. Phys. Res. B. 2001, 184, 337-346. [CrossRef]

45. Apel, P.Y.; Blonskaya, I.V.; Dmitriev, S.N.; Mamonova, T.I.; Orelovitch, O.L.; Sartowska, B.; Yamauchi, Y. Surfactant-controlled etching of ion track nanopores and its practical applications in membrane technology. Radiat. Meas. 2008, 43, 552-559. [CrossRef]

46. NIST TRC TDE Standart Reference Database 103a; Aspen Properties ${ }^{\circledR}$; TIPS RAS: Moscow, Russia, 2021.

47. Orelovitch, O.L.; Apel, P.Y.; Sartowska, B. New methods of track membrane treatment in the preparation of samples for further observation with scanning electron microscopy. J. Microsc. 2006, 224, 100-103. [CrossRef]

48. Owens, D.K.; Wendt, R.C. Estimation of the surface free energy of polymers. J. Appl. Polym. Sci. 1969, 13, 1741-1747. [CrossRef]

49. Fowkes, F.M. Attractive forces at interfaces. Ind. Eng. Chem. 1964, 56, 40-52. [CrossRef]

50. Hulterström, A.K.; Berglund, A.; Ruyter, I.E. Wettability, water sorption and water solubility of seven silicone elastomers used for maxillofacial prostheses. J. Mater. Sci. Mater. Med. 2008, 19, 225-231. [CrossRef]

51. Arikan, E.; Holtmannspötter, J.; Zimmer, F.; Hofmann, T.; Gudladt, H.J. The role of chemical surface modification for structural adhesive bonding on polymers-Washability of chemical functionalization without reducing adhesion. Int. J. Adhes. Adhes. 2019, 95, 102409. [CrossRef]

52. Apel, P.Y.; Blonskaya, I.V.; Orelovitch, O.L.; Ramirez, P.; Sartowska, B.A. Effect of nanopore geometry on ion current rectification. Nanotechnology 2011, 22, 175302. [CrossRef] [PubMed]

53. Volkov, V.V.; Lebedeva, V.I.; Petrova, I.V.; Bobyl, A.V.; Konnikov, S.G.; Roldughin, V.I.; van Erkel, J.; Tereshchenko, G.F. Adlayers of palladium particles and their aggregates on porous polypropylene hollow fiber membranes as hydrogenization contractors/reactors. Adv. Colloid Interface Sci. 2011, 164, 144-155. [CrossRef]

54. Kobayashi, I.; Yasuno, M.; Iwamoto, S.; Shono, A.; Satoh, K.; Nakajima, M. Microscopic observation of emulsion droplet formation from a polycarbonate membrane. Colloids Surf. A Physicochem. Eng. Asp. 2002, 207, 185-196. [CrossRef]

55. Vladisavljević, G.T. Preparation of microemulsions and nanoemulsions by membrane emulsification. Coll. Surf. A Physicochem. Eng. Asp. 2019, 579, 123709. [CrossRef]

56. Vladisavljević, G.T. Fabrication of nanoemulsions by membrane emulsification. Nanoemulsions 2018, 287-346. [CrossRef]

57. Kuzmanović, B.; Kuipers, N.J.; de Haan, A.B.; Kwant, G. Reactive extraction of alcohols from apolar hydrocarbons with aqueous solutions. Tsinghua Sci. Technol. 2006, 11, 222-227. [CrossRef]

58. Zhu, Z.; Bai, W.; Qi, P.; Dai, Y.; Wang, Y.; Cui, P.; Gao, J. Liquid liquid equilibrium data for the separation of acetone from n-heptane using four imidazolium-based ionic liquids. J. Chem. Eng. Data. 2019, 64, 1202-1208. [CrossRef] 